the use of paid childminders and the use of private schemes account for most of the socioeconomic gradient in child care arrangements. The most affluent parents pay other people to look after their children. Three cohort studies have examined the relative safety of out-of-home day care and home care. The two studies conducted in the USA found that the injury rate for children in day care was lower than that of children cared for at home (presumably by their mothers).$^{78} \mathrm{~A}$ Swedish study however, found the opposite, with a small but significantly increased risk during day care. ${ }^{9}$ While the results are to some degree conflicting, they certainly provide no support for a causal role of low parental supervision.

Socioeconomic gradients in the use of alternatives to parental care are also apparent for school aged children. ${ }^{4}$ Among mothers working full time, $67 \%$ of those with higher education make alternative care arrangements for children 5-11 years, compared with $46 \%$ of unqualified mothers. Once again, inability to pay for non-parental care appears to be the most important factor. The lack of affordable alternatives to parental care may contribute to the higher pedestrian injury rates for children from poor families. Adult accompaniment on the school-home journey is associated with a decreased risk of pedestrian injury, ${ }^{10}$ and Towner $e t$ al found that children from deprived households were much less likely to be accompanied to and from school by an adult. ${ }^{11}$ Whereas affluent working parents can employ childminders to meet their children from school, those on lower incomes do not have this option.

In the light of these data, what might be said about calls for greater parental supervision in the context of childhood injury prevention? Children do need to be cared for and supervised, but there is not a scrap of evidence that this supervision is more effective when provided by parents as opposed to any other carer. Indeed, the available evidence suggests quite the opposite. Having no empirical basis, calls for more parental supervision can only be interpreted as ideological statements. As is often the case with assertions whose power resides in their 'obviousness' lurking in the background are values. In this case the values concern the proper position of women in society and the balance of responsibility for child safety between the individual and the society.

1 Lawson SD. Accidents to young pedestrians: distributions, circumstances, consequences and scope for countermeasures. Birmingham: AA Foundation for Road Safety Research, 1990.

2 Haberal MA. An eleven year survey of electrical burn injuries. F Burn Care Rehabil 1995; 16: 43-8.

3 American Medical Association Board of Trustees. Use of infant walkers. Am $\mathcal{f}$ Dis Child 1991; 145: 933-4.

4 Bridgwood A, Savage D. General household survey 1991. on: A, Sava

5 Central Statistical Office. Social trends 25: 1995 edition. London: HMSO, 1995

6 Woodroffe C,. Glickman M, Barker M, Power C. Children, teenagers and health: the key data. Buckingham: Open University Press, 1993

7 Rivara FP, DiGuiseppi C, Thompson RS, Calonge N. Risk of injury to children less than five years of age in day care versus home care setting. Pediatrics 1989; 84: 1011-6.

8 Gunn WJ, Pinsky PF, Sacks JJ, Schonberger LB. Injurie and poisonings in out-of-home child care and home care. Am 7 Dis Child 1991; 145: 779-81.

9 Sellstrom E, Bremberg S, Chang A. Injuries in Swedish day care centres. Proceedings of the International Conference on Child Day Care Health: Science, Prevention and Practice. (15-17 June 1992, Atlanta.) Atlanta: Cente

10 Roberts I. Adult accompaniment and the risk of pedestrian injury on the school-home journey. Injury Prevention 1995; 1: 242-4.

11 Towner EML, Jarvis SN, Walsh SSM, Aynsley-Green A Measuring exposure to injury risk in schoolchildren aged 11-14. BMF 1994; 308: 449-52.

\title{
DISSENT
}

\section{Is there more to parental supervision than political incorrectness?}

\author{
Sara Levene
}

Roberts makes two arguments in his criticism of parental supervision as a child safety strategy (p 9). Firstly, the onus of parenting falls on mothers, so 'parental' supervision actually means 'maternal' supervision. Secondly, supervision provided by competent adults other than carers may be more effective than parental supervision.

The first argument revolves around the use of language rather than discussing important aspects of supervision. If authors use the term 'parental' supervision, it may be that they are simply being politically correct, afraid to reveal their true opinion - that it is mothers who should be the more careful or responsible supervisors. Alternatively, perhaps they are being politically incorrect. They may actually mean 'supervision by a carer' but have not trained themselves in this use of language. Does this really matter?

To me the much more important question is: how effective is supervision as a safety strategy? If it is reasonably effective, it stands to reason that all adults should assiduously supervise children in their care. Conversely, supervision might be proved to be an extremely poor safety 
strategy - one that can fail too often and too easily.

In considering this question we need to remember that there are different levels of supervision. The most intense is sitting with a child and assisting him or her directly, as when young children are cooking or cutting. Another is watching them continuously, as when a toddler is in the bath. Still another is being in the same room, but doing something else fairly routine practise for preschool children. Finally, there is supervision from a distance being in another room but keeping an ear open for screams, or, more ominously, silence. This is a common strategy with older children.

The first two scenarios can provide good protection, but only if the supervisor's concentration does not slip. Every accident and emergency doctor has heard the cry 'I only turned my back for a minute'. The latter two scenarios provide even more opportunities for mishap. The wrong level of supervision may be selected, as in a recent incident in the UK when a mother tried to supervise her toddler at play on a river bank by occasional glances out of a window; fortunately the child was rescued from near drowning some miles downstream. Clearly, supervision can fail to give the same protection that may be afforded by environmental change in some instances.

On the other hand, supervision could prove to be a good safety strategy. It is difficult to see how some home accidents, such as bath tub drownings, could be prevented in any other way. There is also positive scientific evidence of the value of supervision in other fields. For example, lifeguards may reduce drowning deaths in public swimming pools ${ }^{1}$ or on beaches, ${ }^{23}$ and accompanied child pedestrians may be at reduced risk. ${ }^{4}$ Other authors have found an association between lack of supervision and injuries to young children in play settings ${ }^{5}$ or in common domestic accidents. ${ }^{6}$

It is, however, unfortunately very difficult to obtain good data on supervision. The presence of adults in the house, let alone in the same room, at the time of a child's injury is rarely recorded. I am not aware of any intervention directly addressing the issue of supervision exclusively. Therefore, the potential for supervision to be effective is indicated, but not clearly demonstrated.

I suggest therefore that there are two topics that could be explored to better effect that the ideological or semantic issues that Roberts raises. Firstly, how effective is supervision as a safety strategy? Secondly, if children are safer with trained carers than with parents, why could structured programmes of parent education not improve the effectiveness of parents are carers?

1 Kemp A, Sibert J. Drowning and near drowning in the United Kingdom: lessons for prevention. $B M F$ 1992; 304 1143-6.

2 Patrick M, Bint M, Pearn J. Salt water drowning and near drowning accident involving children. Med $\mathcal{F}$ Aust 1979; 1: $61-4$.

3 Spyker D. Submersion injury. Epidemiology, prevention and management. Pediatr Clin North Am 1985; 32 113-25.

4 Roberts I. Adult accompaniment and the risk of pedestrian injury on the school-home journey. Injury Prevention injury on the sch

5 King K, Ball D. A holistic approach to accident and injury prevention in children's playgrounds. London: LSS, 1989. prevention in children's playgrounds. London: LSS, 1989.
Alwash R, McCarthy M. How do child accidents happen? Alwash R, McCarthy M. How do child acciden
Health Education fournal 1987; 46: 169-71.

\section{Advice from an emergency medical technician}

I am a firefighter/EMT-Basic but am also a Combat Medic for the US army (now in the US Army Reserves). In the army, I do the trauma skills of a paramedic. We have found that the pulse-blood pressure correlation is about $95 \%$ effective in trauma patients and about $85 \%$ effective in non-trauma patients. For us, this is called the 'field expedient method' of obtaining a systolic blood pressure. We often don't have time to take a patient's blood pressure while being fired upon and others are being injured as well. We need to know minimum pressures to decide what life saving procedures can be done as well as drug administration. This method has been very effective in determining the minimum pressure on trauma patients I have dealt with in the field, in air ambulance, and in the city. Certainly this method cannot replace the need for auscultated blood pressure; it is only to be used when no blood pressure cuff is available or when it is impossible to use it. This is the scale: if palpable radial pulse present, systolic blood pressure is at least $80 \mathrm{mmHg}$. If radial pulse is absent, palpate carotid pulse. If carotic pulse present, systolic blood pressure is at least $70 \mathrm{mmHg}$. If radial and carotid pulses are absent, palpate femoral pulse. If femoral pulse is present, systolic blood pressure is at least $60 \mathrm{mmHg}$. I'm certainly not a doctor but I do form my opinions from medical experience (Jason Johnson Polk, County Fire District \#1) (CCSN BBS). 